\title{
Topography-based flow-directional roughness: potential and challenges
}

\author{
Sebastiano Trevisani ${ }^{1}$ and Marco Cavalli $^{2}$ \\ ${ }^{1}$ University IUAV of Venice, DACC Department, Dorsoduro 2206, 30123 Venice, Italy \\ ${ }^{2}$ National Council of Research of Italy, Research Institute for Geo-Hydrogeological Protection, \\ Corso Stati Uniti 4, 35127 Padua, Italy \\ Correspondence to: Sebastiano Trevisani (strevisani@iuav.it)
}

Received: 26 November 2015 - Published in Earth Surf. Dynam. Discuss.: 10 December 2015

Revised: 10 March 2016 - Accepted: 5 April 2016 - Published: 21 April 2016

\begin{abstract}
Surface texture analysis applied to high-resolution digital terrain models (HRDTMs) is a promising approach for extracting useful fine-scale morphological information. Surface roughness, considered here as a synonym of surface texture, can have a discriminant role in the detection of different geomorphic processes and factors. Very often, the local morphology presents, at different scales, anisotropic characteristics that could be taken into account when calculating or measuring surface roughness. The high morphological detail of HRDTMs permits the description of different aspects of surface roughness, beyond an evaluation limited to isotropic measures of surface roughness. The generalization of the concept of roughness implies the need to refer to a family of specific roughness indices capable of capturing specific multiscale and anisotropic aspects of surface morphology. An interesting set of roughness indices is represented by directional measures of roughness that can be meaningful in the context of analyzed and modeled flow processes. Accordingly, we test the application of a flow-oriented directional measure of roughness based on the geostatistical bivariate index MAD (median of absolute directional differences), which is computed considering surface gravity-driven flow direction. MAD is derived from a modification of a variogram and is specifically designed for the geomorphometric analysis of HRDTMs. The presented approach shows the potential impact of considering directionality in the calculation of roughness indices. The results demonstrate that the use of flow-directional roughness can improve geomorphometric modeling (e.g., sediment connectivity and surface texture modeling) and the interpretation of landscape morphology.
\end{abstract}

\section{Introduction}

With advanced geomorphometric techniques applied to highresolution digital terrain models (HRDTMs), such as those derived via airborne lidar (i.e., an airborne laser scanner, ALS) (Hofle and Rutzinger, 2011), it is possible to retrieve relevant information on fine-scale morphology (Cavalli et al., 2013b; Cavalli and Marchi, 2008; Frankel and Dolan, 2007; Glenn et al., 2006; Lashermes et al., 2007; Trevisani et al., 2009, 2012, 2015). HRDTMs can cover large areas with very high spatial resolution (pixel size less than or equal to $2 \mathrm{~m}$ ) and vertical accuracy (standard deviation of the vertical error less than $0.3 \mathrm{~m}$ ). ALS surveys specifically designed for smaller areas (tens of square kilometers), depending on ground cover conditions and survey characteristics, can considerably increase the resolution and accuracy of DTMs, permitting DTMs with a reliable pixel size of $0.5 \mathrm{~m}$ and a vertical accuracy $(1 \sigma)$ less than $0.1 \mathrm{~m}$. On the extreme end, very high resolution DTMs can be obtained by means of terrestrial laser scanners or structure-from-motion photogrammetry (Westoby et al., 2012) methodologies. These products are frequently applied in the study of riverbed grain size distribution (e.g., Cavalli and Tarolli, 2011) or in geomechanics (e.g., Teza et al., 2015; Jaboyedoff et al., 2010). Most frequently, the HRDTMs derived by means of ALS are typically a 2.5 -D representation of surface topography, digitally 
stored as a raster image. In this work, we are expressly referring to this typology of product; however, the same concepts, given proper data manipulation approaches (e.g., Pollyea and Fairley, 2011), can be applied to true 3-D representations of surface morphology. The HRDTMs are capable of capturing fine-scale morphologies that are relevant for the analysis and modeling of the processes and factors that influence the morphological evolution of landscapes. By means of geomorphometric methodologies (Pike, 2000), it is possible to extract information related to these fine-scale morphologies and obtain very useful indices from geomorphologic and geological points of view; moreover, fine-scale morphology-related indices have an interesting potential from the perspective of land management, geo-engineering and geo-environmental issues (Booth et al., 2009; Glenn et al., 2006; Jaboyedoff et al., 2010; McGarigal et al., 2009; McKean and Roering, 2004; Teza et al., 2015).

The local fine-scale morphology represented in HRDTMs can be interpreted and analyzed in terms of surface/image texture (Herzfeld and Higginson, 1996; Lucieer and Stein, 2005; Trevisani et al., 2009). Surface/image texture analysis techniques have a long record of applications in remote sensing (e.g., Atkinson and Lewis, 2000; Balaguer et al., 2010; Garriges et al., 2006; Herzfeld, 2008; Woodcock et al., 1988), image analysis and materials science (e.g., surface metrology; Gadelmawla et al., 2002). Local texture analysis conducted on HRDTMs can furnish relevant fine-scale morphological information (Trevisani et al., 2012), focused on specific aspects and scales of surface morphology.

Surface texture is linked to the concept of surface roughness, which, depending on the authors and disciplines involved (e.g., Cavalli et al., 2008; Grohmann et al., 2011; Smith, 2014; Trevisani et al., 2012; Trevisani and Rocca, 2015; Pollyea and Fairley, 2011), can be considered an aspect of surface texture, generally related to short-range/finegrain spatial variability in surfaces or as a synonym of surface texture. In this work, we follow the second viewpoint, thus considering "roughness" as a synonym of "texture". Consequently, given the multiscale and anisotropic character of surface morphology, it is not possible to define a single geomorphometric index quantifying roughness; conversely, it is necessary to clearly state which aspect of surface roughness the used roughness index is intended for measuring. Real topographic surfaces often show a high complexity in local surface roughness with multiscale and anisotropic characteristics. The anisotropy in surface morphology (Fig. 1) is an important aspect that can be characterized (Roy et al., 2015; Trevisani et al., 2009, 2012; Trevisani and Rocca, 2015) and considered when calculating indices of roughness. Most of the roughness indices proposed in the literature (e.g., Berti et al., 2013; Grohmann et al., 2011) implicitly consider roughness as an isotropic parameter; an exception is represented by the roughness calculated from slope (Frankel and Dolan, 2007). The generalization of the concept of roughness opens the possibility of considering anisotropy in surface texture
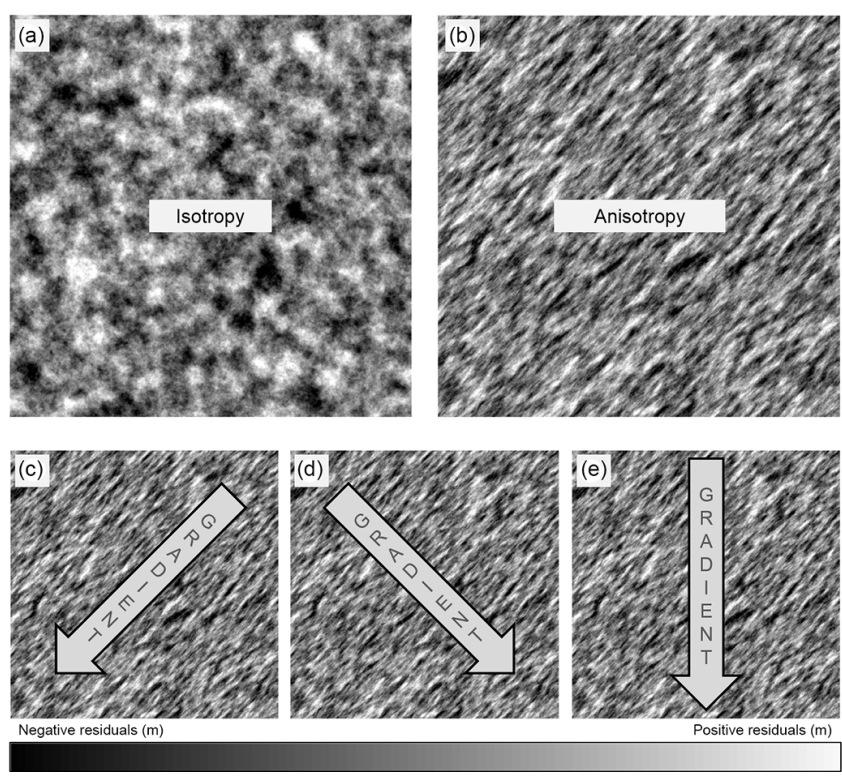

Figure 1. Anisotropy in surface texture and impact on surface flow. Synthetic residual DTMs with isotropic (a) and anisotropic (b) surface texture. In the presence of anisotropy, the effective flow is influenced by the angle between the direction of the gravity gradient with respect to the direction of maximum continuity (DMC) of surface morphology. (c) Gradient aligned to the DMC (minimum resistance), (d) gradient orthogonal to the direction of DMC (maximum resistance), and (e) gradient at an angle with respect to the DMC (deflection of flow lines with respect to gradient direction).

and calculating directional roughness indices (e.g., Trevisani et al., 2009, 2012; Trevisani and Rocca, 2015).

The characterization of roughness anisotropy can be relevant for both geomorphologic interpretation and the analysis and modeling of gravity-driven surface flow processes. In the context of flow processes, the anisotropy in surface roughness influences the impedance to flow. In the presence of an anisotropic surface texture, the resistance to flow changes according to the angle between the gradient and the direction of maximum continuity (i.e., the direction of lower roughness). The minimum resistance to flow is encountered when the gradient (Fig. 1c) is in the same direction as the maximum continuity and the maximum resistance is found when the gradient (Fig. 1d) is in the direction of maximum roughness. Moreover, when the flow gradient is at an angle with respect to the surface texture maximum continuity direction, the real flow lines can be deflected with respect to the gradient direction (Fig. 1e); this is an important aspect that deserves consideration in upscaling procedures, where the impedance to surface flow can be considered a tensor property, analogous to hydraulic conductivity (Fetter, 2000).

Given these considerations, the aim of this work is to evaluate the effectiveness and further developments of short-range flow-directional roughness indices in a hydrogeomorphological context and their potential application to 
complex indices and models. To this end, the first objective (case study "Site 1") is to investigate the differences between flow-directional and isotropic roughness in terms of their statistical and spatial distribution, also in relation to morphologies and processes characterizing the study site. Finally, the second objective (case study "Site 2") is to explore the use of flow-directional roughness as an impedance factor in a sediment connectivity index that, in its formulation, directly uses surface roughness as a proxy of the impedance to water and sediment fluxes (Cavalli et al., 2013a).

\section{Materials and methods}

\subsection{MAD and computation of flow-directional roughness}

For the evaluation of flow-directional roughness, we use a robust bivariate geostatistical index (MAD, median absolute differences; Trevisani and Rocca, 2015) specifically designed for the analysis of HRDTMs. We limit the study to short-range directional roughness, avoiding multiple-scale evaluations, to reduce the number of influencing factors. The study of multiscale directional roughness represents a possible second stage of research that is worth exploring. Spatial continuity indices such as the variogram (Cressie, 1993) have been widely applied in the context of remote-sensing and geomorphometry because they allow the description of different aspects of surface/image texture by means of multiscale and directional indices.

For the derivation of short-range roughness, we use the MAD index, Eq. (1), by means of a specially developed GIS tool (freely available online, https://github.com/cageo/ Trevisani-2015), specifically designed for the analysis of HRDTMs. MAD, similarly to the well-known variogram (Eq. 2), is calculated considering the differences between spatial pairs of values $\left(Z\left(\boldsymbol{u}_{\alpha}\right)\right.$, with the vector $\boldsymbol{u}$ indicating the coordinates), which in this context represent residual elevations; the differences are calculated between pairs of values separated by a given separation vector $\boldsymbol{h}$ (named the lag h) (Fig. 2). For a given local search neighborhood (generally a circular moving window) and a given lag $\boldsymbol{h}$, the set of $N(\boldsymbol{h})$ pairs of residual elevations separated by lag $\boldsymbol{h}$ in the neighborhood is used to calculate the bivariate indices (Eqs. 1 and 2).

$\operatorname{MAD}(\boldsymbol{h})=\operatorname{median}(|\Delta(\boldsymbol{h})|)=$

$\left\{\begin{array}{l}\left|\Delta(\boldsymbol{h})_{\alpha=(N(\boldsymbol{h})+1) / 2}\right| \text { with } N(\boldsymbol{h}) \text { odd } \\ 1 / 2\left(\mid\left(\Delta(\boldsymbol{h})_{\alpha=N(\boldsymbol{h}) / 2}|+| \Delta(\boldsymbol{h})_{\alpha=N(\boldsymbol{h}) / 2+1} \mid\right) \text { with } N(\boldsymbol{h}) \text { even, }\right.\end{array}\right.$

where $\left|\Delta(\boldsymbol{h})_{\alpha}\right|=\left|z\left(\boldsymbol{u}_{\alpha}\right)-z\left(\boldsymbol{u}_{\alpha}+\boldsymbol{h}\right)\right|$, with the values $\left|\Delta(\boldsymbol{h})_{\alpha}\right|$, $\alpha=1, \ldots, N(\boldsymbol{h})$ sorted into ascending order and $|\Delta(\boldsymbol{h})|$ the set of the $N(\boldsymbol{h})$ absolute differences with a separation vector $\boldsymbol{h}$, i.e., $\left\{\mid \Delta(\boldsymbol{h})_{\alpha} \| \alpha=1, \ldots, N(\boldsymbol{h})\right\}$.

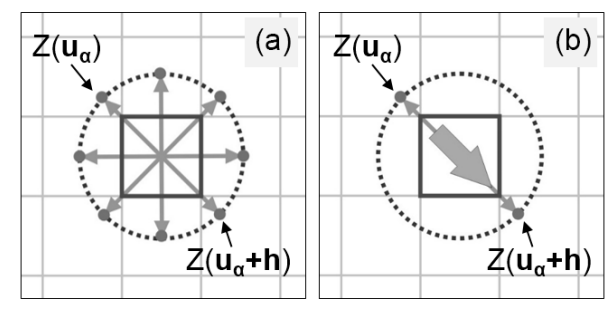

Figure 2. Directional differences with a separation distance of 2 pixels for the calculation of short-range roughness indices. The differences are derived from pairs of values located on opposite sides of the dashed circle. The values of directional differences are associated with the central pixel (highlighted in black; see Trevisani, 2015). (a) Directional differences for omnidirectional roughness and (b) directional differences for the calculation of flow-directional roughness (local flow direction indicated by the thick gray-filled arrow).

$$
\begin{aligned}
\text { Variogram } & =\gamma(\boldsymbol{h})=\frac{1}{2 N(\boldsymbol{h})} \sum_{\alpha=1}^{N(\boldsymbol{h})}\left[z\left(\boldsymbol{u}_{\alpha}\right)-z\left(\boldsymbol{u}_{\alpha}+\boldsymbol{h}\right)\right]^{2} \\
& =1 / 2 \cdot \operatorname{mean}\left(\Delta(\boldsymbol{h})^{2}\right),
\end{aligned}
$$

with

$\Delta(\boldsymbol{h})_{\alpha}=z\left(\boldsymbol{u}_{\alpha}\right)-z\left(\boldsymbol{u}_{\alpha}+\boldsymbol{h}\right)$

and $\Delta(\boldsymbol{h})^{2}$ the set of $N(\boldsymbol{h})$ squared differences with a separation vector $\boldsymbol{h}$, i.e.,

$\left\{\left[\Delta(\boldsymbol{h})_{\alpha}\right]^{2} \mid \alpha=1, \ldots, N(\boldsymbol{h})\right\}$.

$\operatorname{MAD}(\boldsymbol{h})$ is the median of the set absolute differences in residual elevation; in contrast, the variogram is half of the mean of the set of squared differences. The formulation of MAD permits a more robust description of spatial variability than the variogram (Chilès and Delfiner, 2012), which is particularly useful with noisy and highly spatially nonstationary data (Trevisani and Rocca, 2015). MAD (Eq. 1), similarly to the variogram (Eq. 2), as a function of the separation vector ( $\operatorname{lag} \boldsymbol{h})$, is a 2-D function that is dependent on the modulus and the direction of $\boldsymbol{h}$, which can be represented in the same way as a variogram map (Trevisani et al., 2009).

MAD and the variogram should be calculated from a residual DTM, obtained by removing large-scale variations from the DTM (Cavalli and Marchi, 2008; Frankel and Dolan, 2007; Grohmann et al., 2011; Hiller and Smith, 2008). This is commonly performed by smoothing the original DTM and subtracting the smoothed version from the original DTM. The method of smoothing and, above all, the degree of smoothing affect the wavelengths and amplitude of the morphologies remaining in the residual DTM. Consequently, the derivation of the residual DTM is a critical task that should be calibrated to the object of the study and to the features required for outlining. In this work, we are interested in shortrange roughness, and the derivation of the residual DTM has 
been addressed by using a simple approach based on multipass moving averages using small search windows (e.g., $5 \times 5$ ) (Trevisani et al., 2010).

To simplify the analysis and focus on anisotropy, we limit the study to short-range roughness computed using a local window (circular, radius 3 pixels; Trevisani and Rocca, 2015) with a lag modulus of 2 pixels (Fig. 2). We derive isotropic measures of short-range roughness $\left(R_{\text {iso }}\right)$ by considering pairs of values of residual elevation separated by 2 pixels in all directions (Fig. 2a); in addition, we derive flow-directional measures of short-range roughness $\left(R_{\text {flow }}\right)$ by considering pairs of values of residual elevation separated by 2 pixels in the flow direction (Fig. 2b).

The simpler approach is to compute flow direction from the DTM or, to obtain less erratic flow directions, from the smoothed DTM with a D8 algorithm. The methodology can be extended using flow directions determined with other approaches such as the multiple-flow $D$ infinity (Tarboton, 1997) or derived from physically based numerical models. Moreover, the preferential directions used for roughness calculations can be representative of processes other than gravity-driven surface flow: e.g., wildfire spread direction, wind direction, and ecological pathways. In this work, the main steps followed for flow-directional calculation are (i) computation of flow directions by means of the D8 algorithm applied to the original or smoothed DTM; (ii) computation of directional differences using the local flow directions and considering a lag of 2 pixels ( $4 \mathrm{~m}$ case Study 1, $2 \mathrm{~m}$ case Study 2) from the residual DTM; and (iii) computation of local measures of flow-directional roughness $\left(R_{\text {flow }}\right)$ by means of the MAD index, using a circular search window with a radius of 3 pixels (a total of 29 pairs are used for the calculation of MAD; see Trevisani, 2015).

\subsection{The sediment connectivity index}

The adimensional index of sediment connectivity (IC), originally developed by Borselli et al. (2008), is a distributed GIS-based index mainly focused on the influence of topography on sediment connectivity. The connectivity aims to represent the linkage between different parts of the catchment (i.e., hillslopes and features of interest such as catchment outlets, main channel networks or a given cross section along the channel). IC (Fig. 3) is defined by the logarithm of the ratio between an upslope ( $D_{\text {up }}$, units in $\left.\mathrm{m}\right)$ and a downslope $\left(D_{\mathrm{dn}}\right.$, units in $\mathrm{m}$ ) component expressing, respectively, the potential for downward routing of the sediment-produced upslope and the sediment flux path length to the nearest target or sink. A weighting factor $(W)$ appears in both components of the IC to model the impedance to runoff and sediment fluxes. Cavalli et al. (2013a) proposed some changes to the original index to adapt it to mountain catchments and its use with HRDTMs, with one of the main modifications in regard to the choice of the weighting factor. Borselli et al. (2008) used the $\mathrm{C}$ factor of the USLE-RUSLE models, which is related to vegetation

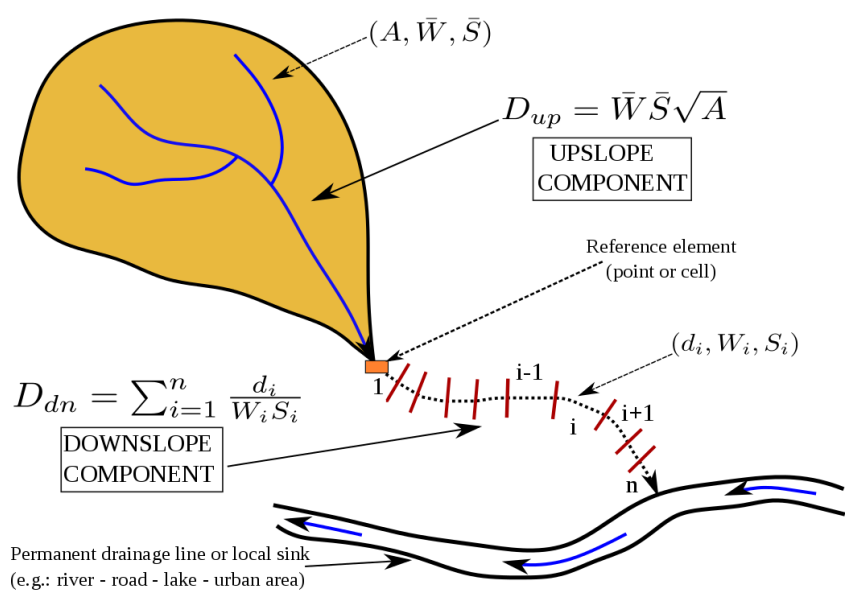

Figure 3. Definition of the upslope and downslope component of the index of connectivity (from Crema et al., 2015; modified after Borselli et al., 2008). A: contributing area to the reference element; $W_{i}$ : weighting factor of the $i$ th pixel; $W$ : average weighting factor of the contributing area; $S_{i}$ : slope of the $i$ th pixel; $S$ : average slope of the contributing area.

cover and management; in addition, Cavalli et al. (2013a) decided to adopt a local measure of topographic surface roughness calculated as the standard deviation of the residual topography at a scale of a few meters. The residual topography was computed as the difference between the original DTM and an averaged version of the DTM. A roughness-based weighting factor was chosen because, in mountain catchments, a large variety of surface roughness exists, depending on the characteristics of outcropping rocks and debris cover, especially in large unvegetated areas where a land-use-based $W$ does not provide differences in the impedance to sediment transport (Cavalli et al., 2013a).

The index of connectivity in its original formulation is expressed as the logarithm of the ratio (i.e., $\mathrm{IC}=\log _{10}\left(D_{\mathrm{up}} / D_{\mathrm{dn}}\right)$. The use of the logarithm in the index of connectivity has the advantage of reducing the high positive skewness that generally characterizes the statistical distribution of the ratios between $D_{\text {up }}$ and $D_{\mathrm{dn}}$; the distorted distribution is a structural characteristic in mountain environments, given that the $D_{\text {up }}$ component inevitably has the tendency to decrease exponentially with increasing $D_{\mathrm{dn}}$. From an interpretative and modeling viewpoint, we can represent the connectivity index by directly using the ratio between $D_{\text {up }}$ and $D_{\mathrm{dn}}$, with values trimmed to a maximum value of 1 . The revised representation of the connectivity index, named here DC (degree of connectivity), is then expressed as follows:

$\left\{\begin{array}{l}\mathrm{DC}=\frac{D_{\mathrm{up}}}{D_{\mathrm{dn}}} \text { with } \frac{D_{\mathrm{up}}}{D_{\mathrm{dn}}} \leq 1 \\ \mathrm{DC}=1 \text { with } \frac{D_{\mathrm{up}}}{D_{\mathrm{dn}}}>1,\end{array}\right.$

with $0 \leq \mathrm{DC} \leq 1$. 

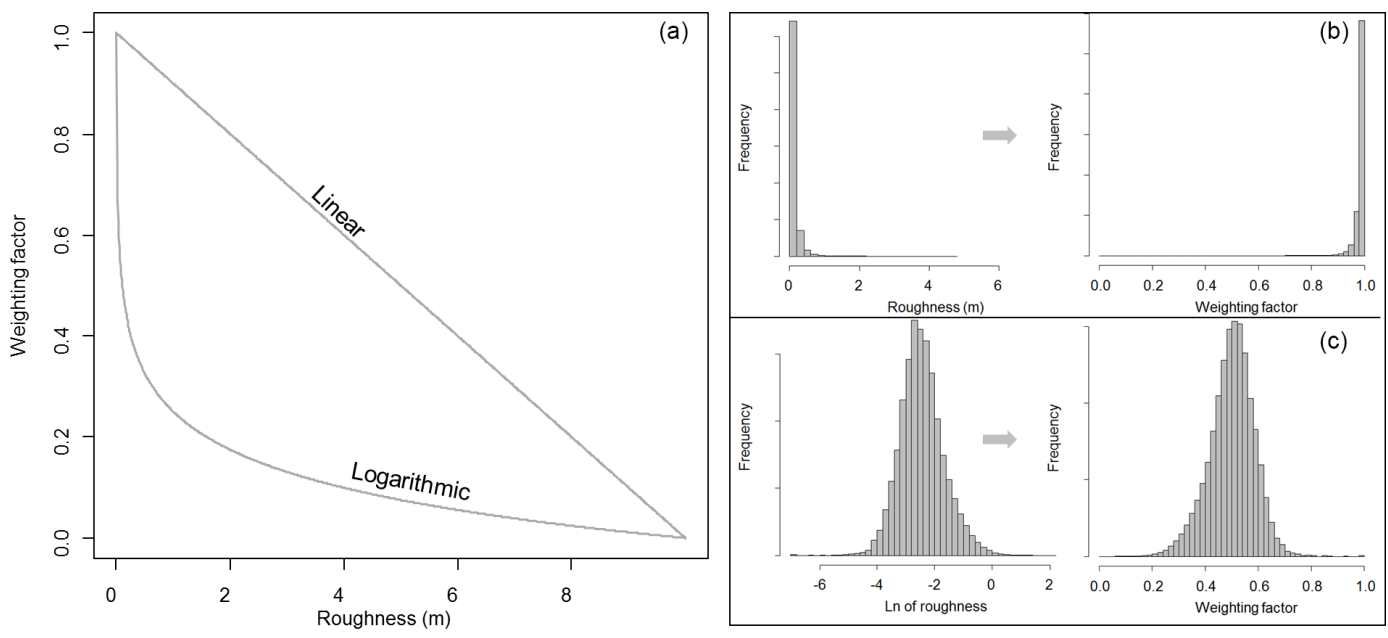

Figure 4. Mapping from roughness values to weighting factor. (a) Mapping curves (supposing roughness variation in the range from 0 to $10 \mathrm{~m}$ ). The impact of the two different transformations of the weighting factor histogram is represented in (b) (linear) and (c) (logarithmic) for experimental roughness values $\left(R_{\text {flow }}\right)$.

This revised representation of the index does not alter the whole process of calculation of the index of connectivity; however, it permits a description of connectivity in terms of probability and implies a different interpretation of the upslope and downslope components than the one proposed by Borselli et al. (2008). Because $D_{\text {up }}$ is based on a stream power relationship, it can be interpreted as the potential distance that a unit of sediment located in a point of interest would run on a perfectly smooth surface with slope 1 (given a hydraulically significant idealized meteoric impulse). Additionally, $D_{\mathrm{dn}}$ represents the effective weighted distance, considering the effective slope and roughness that the unit of sediment has to travel from the point of interest to the defined sink. Consequently, when the ratio $D_{\text {up }} / D_{\mathrm{dn}}$ is equal to or above 1, the potential traveled distance is higher than the effective distance, and the sediment unit is completely connected, or, in probabilistic terms, has a probability of 1 to arrive at the target given a significant flow impulse. Alternatively, the values below 1 indicate that the potential distance is lower than the effective distance.

In the original formulation of the connectivity index, the mapping of the weighting factor from roughness values is derived via a linear transformation (Fig. 4) after normalizing the roughness according to Eq. (4):

$W=1-\frac{R}{R_{\max }}$,

where $R$ is the local roughness, which is computed as the standard deviation of the residual DTM calculated with a moving window of $5 \times 5$ pixels.

In the presence of highly positively distorted distributions of roughness (Fig. 4b) typical of mountain environments, mapping by means of Eq. (4) generates values of the weighting factor characterized by a very small range of variation, with values packed toward a weighting factor of 1 . This procedure for deriving $W$ has two-fold side effects: (i) it reduces the impact of the spatial variability in surface roughness on IC, and (ii) it reduces the impact of differences between alternative indices of roughness (e.g., $R_{\text {flow }}$ vs. $R_{\text {iso }}$ ). A mathematical solution is to normalize the natural logarithm of roughness (Fig. 4c) according to Eq. (5):

$W=1-\frac{\operatorname{Ln}(R)-\operatorname{Ln}\left(R_{\min }\right)}{\operatorname{Ln}\left(R_{\max }\right)-\operatorname{Ln}\left(R_{\min }\right)}$,

where $R_{\max }$ and $R_{\min }$ are the maximum and minimum (trimmed to 0.001) roughness among the compared indices.

With this proposed transformation, the weighting factor shows a wider range of variation, reducing the effect of compression of variability.

\subsection{The data sets}

In this work, two different study sites located in an alpine setting in the Italian Alps and related lidar-derived HRDTMs have been used (Fig. 5). The first study site (Site 1), covering an area of $575 \mathrm{~km}^{2}$, was selected for performing a comparative analysis between $R_{\text {flow }}$ and $R_{\text {iso }}$, and for analyzing the differences of site-specific geo-structural settings, morphologies and ground cover. The second study site (Site 2), covering a smaller area of $15 \mathrm{~km}^{2}$, was selected for studying the potential use of $R_{\text {flow }}$ in the context of the sediment connectivity index proposed by Cavalli et al. (2013a).

The study site is located in the province of Trento (northern Italy) and covers $575 \mathrm{~km}^{2}$ of complex and heterogeneous alpine morphology, with elevations ranging from 206 to $3152 \mathrm{~m}$ a.s.l. (Fig. 6). The study area is characterized by variable ground cover typologies, different levels of anthropic influence and a complex geo-structural setting (Castellarin et 


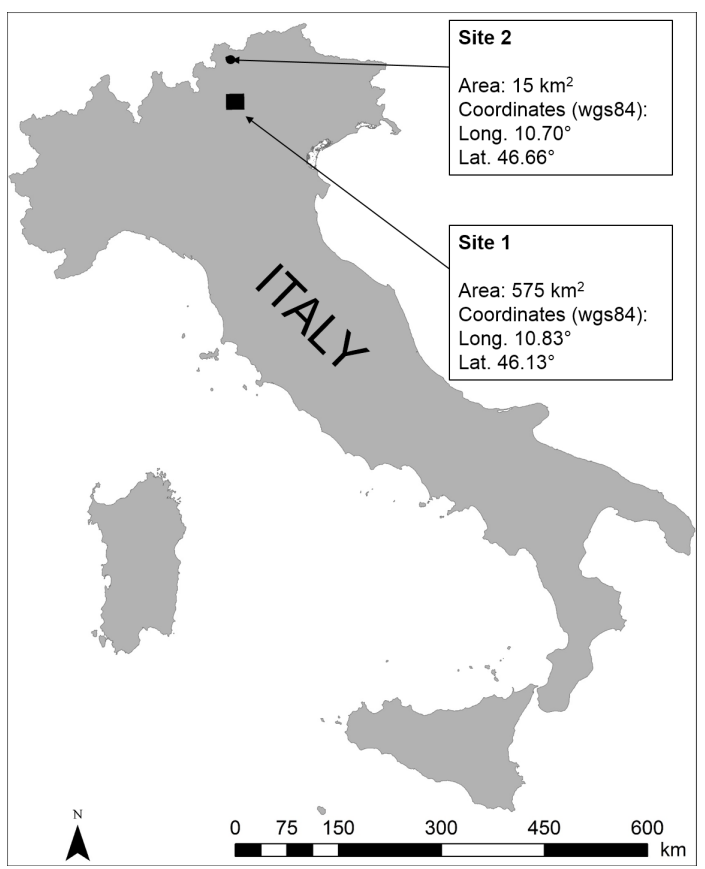

Figure 5. Location of the two case studies and relative coverage areas.

al., 2005). For this area, an HRDTM derived via ALS is available under a Creative Commons 2.5 license provided by the Trento Province (2016). This HRDTM is part of an airborne lidar survey covering the whole of the province of Trento (more than $6500 \mathrm{~km}^{2}$ ) conducted between 2006 and 2007 (Cavalli et al., 2013a, b). In areas of low elevation and those bordering urbanized environments, the HRDTM is available with a pixel size of $1 \mathrm{~m}$ and a reported vertical accuracy of $0.15 \mathrm{~m}(1 \sigma)$; for areas of high altitude and with steep slopes, the HRDTM is available with a resolution of $2 \mathrm{~m}$, and a reported accuracy of $0.3 \mathrm{~m}$. To derive an HRDTM with a homogeneous pixel size, we resampled the $1 \mathrm{~m}$ DTM to $2 \mathrm{~m}$, averaging four neighboring pixels (corresponding to, in the case of uncorrelated Gaussian error, an accuracy of $0.075 \mathrm{~m}$ ).

The reported vertical accuracy of the lidar of the two different typologies of area has to be considered merely indicative. First, the dependency of lidar accuracy on slope and ground cover typology suggests that these values can overor underestimate the true accuracy in relation to local conditions. Another point that deserves to be mentioned is that the vertical accuracy reported does not discriminate between different typology of errors, i.e., whether these are spatially correlated. The presence of a spatially correlated error (e.g., Sofia et al., 2013) has a different impact on measures of surface roughness with respect to an uncorrelated error. In the case of a spatially correlated error, the impact on roughness indices is related to the total amplitude of the error, its correlation length and the lag distance used for the bivariate roughness calculation. The worst scenario is encountered

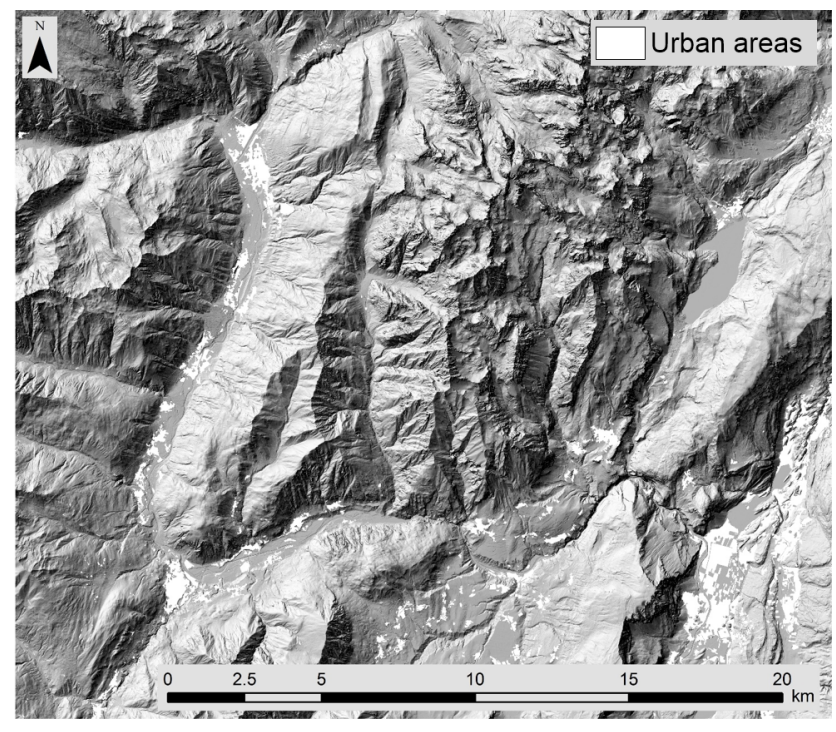

Figure 6. Shaded relief of study area Site 1 (in white: areas of main urbanization and anthropic influence, excluding road network).

when the correlation length of the error is similar to the lag distance used for roughness calculations. Unfortunately, we do not know the correlation lengths of the error, as they are likely spatially variable; however, at least when these have small wavelengths and relevant amplitudes, these are clearly visible in the DTM, e.g., striping artifacts. It should also be considered that, in the evaluation of local surface roughness, the interest is focused on the correct reproduction of surface variability more than in the exact vertical and positional accuracy of the single pixels and/or single lidar points. Consequently, the results of roughness calculations and the comparative analysis between the two roughness indices have to be analyzed critically, taking into consideration the local settings, such as the slope, ground cover typology and presence of evident artifacts on the lidar DTM. Moreover, the analysis of orthophotos (pixel size $0.5 \mathrm{~m}$ ), specifically collected during the lidar survey, and, whenever necessary, site-specific field surveys have been carried out for confirming the results.

The second study site is constituted by two nearby catchments (Gadria and Strimm) covering a total area of approximately $15 \mathrm{~km}^{2}$. The study site is located in the upper Vinschgau-Venosta valley (Autonomous Province of Bozen-Bolzano, Italy) and has been specifically selected because both catchments have been intensely studied from the perspective of sediment dynamics (Comiti et al., 2014; Dell'Agnese et al., 2015), as well as because the sediment connectivity index that we test with flow-directional roughness has been developed in this same area (Cavalli et al., 2013a). This study showed that, because of their contrasting morphology, the catchments are characterized by different patterns of sediment connectivity, showing a higher efficiency of sediment routing in the Gadria catchment. The Gadria catchment, a typical debris-flow catchment, ranges in 


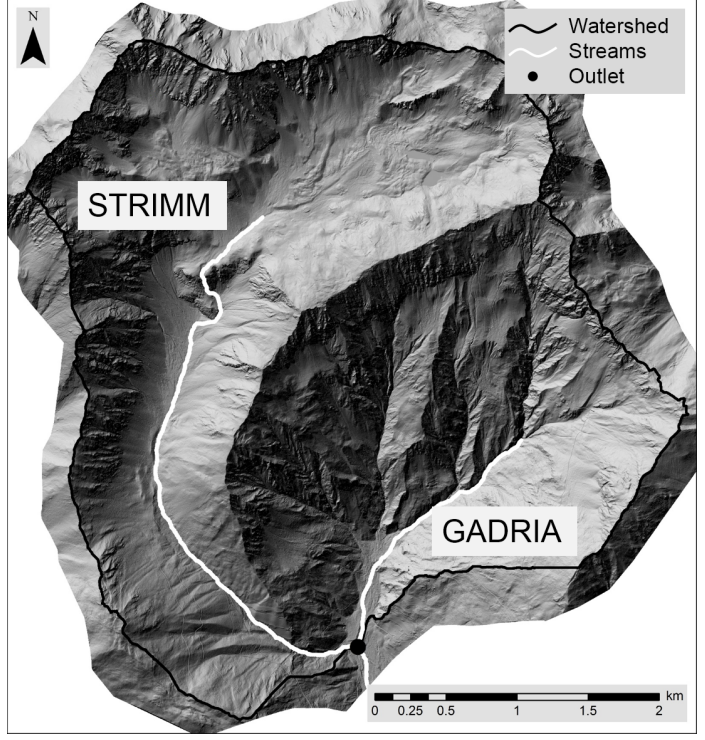

Figure 7. Shaded relief of study area Site 2 (black thick line: watershed; white lines: main streams; black filled circle: basin outlet).

elevation from 1394 to $2945 \mathrm{~m}$ a.s.l., with an average slope of $79.1 \%$. The Strimm catchment, featuring mainly bedload transport, ranges in elevation from 1394 to 3197 m a.s.l., with an average slope of $61.8 \%$. Another reason that led to the choice of this study site is that, following the work of Cavalli et al. (2013a), in which a $2.5 \mathrm{~m}$ DTM was used, a lidar survey was conducted in July 2011, resulting in a filtered point density of 2.28 points $\mathrm{m}^{2}$ in the area, allowing us to derive a $1 \mathrm{~m}$ HRDTM with a calculated vertical accuracy (root mean square error, RMSE) of $0.16 \mathrm{~m}$. More details on the study area can be found in Comiti et al. (2014).

\section{Results and discussion}

\subsection{Comparison between flow-directional roughness and isotropic roughness}

Study Site 1 has been selected for exploring the use of flow-directional roughness for geomorphometric applications. The main target is to evaluate whether the proposed index $\left(R_{\text {flow }}\right)$ furnishes meaningful and distinctive results in comparison to $R_{\text {iso }}$. From this perspective, it is worth evaluating with which morphological features, natural and/or anthropic, the main differences between $R_{\text {flow }}$ and $R_{\text {iso }}$ are associated. A second target is to highlight weaknesses and potentials of the proposed algorithm that require further refinement and development.

For the calculation of $R_{\text {flow }}$ and of $R_{\text {iso }}$, we derived a residual DTM, subtracting a smoothed DTM from the original, which has been smoothed via a two-pass moving window approach (square window), in which the first pass had a window size of 3 pixels and the second pass had a window size

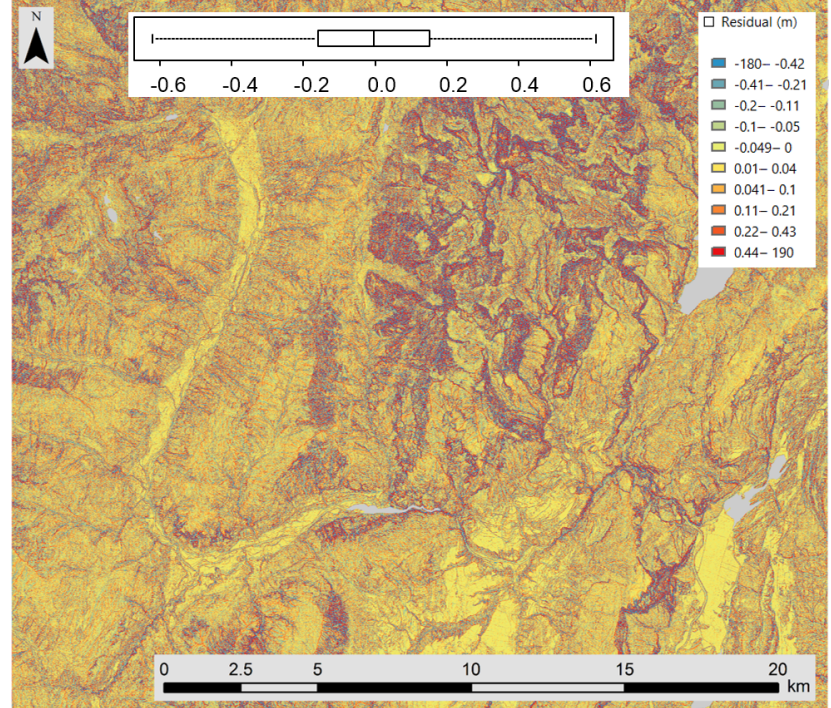

Figure 8. Residual DTM for study Site 1 (color scale according to quantile classification).

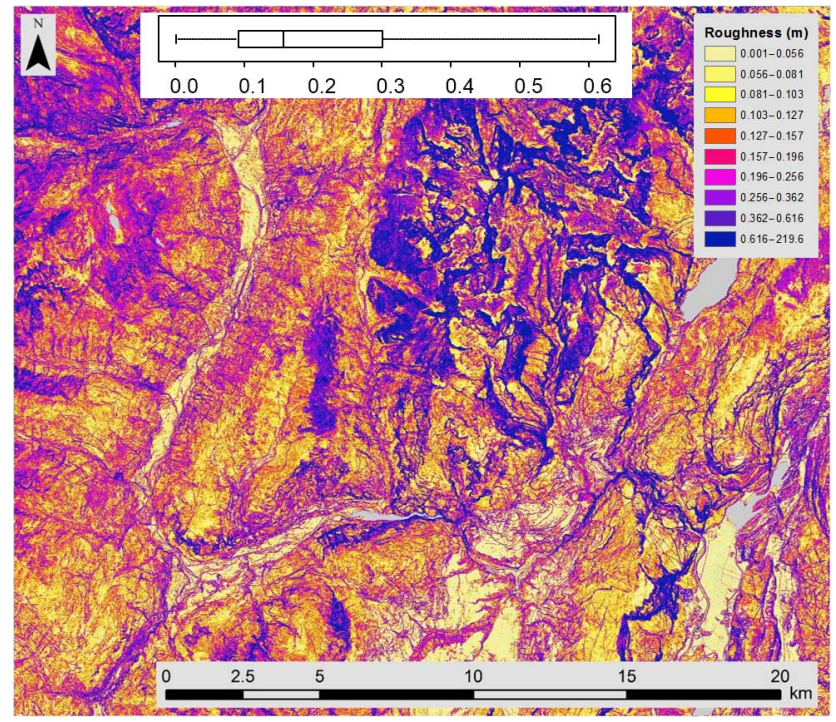

Figure 9. Short-range flow-directional roughness for case study Site 1 (color scale according to quantile classification).

of 5 pixels. The residual DTM highlights (Fig. 8) fine-scale morphologies and represents the input data from which the roughness indices are derived. It is interesting to note (Table 1) that approximately $80 \%$ of the residual elevations are between -0.42 and $+0.43 \mathrm{~m}$, a quite narrow range of variation. The area with higher absolute values of residual topography are located in areas with rocky outcrops and steep slopes, stream channels, terrace scarps and other morphological features inducing sharp changes in morphology.

$R_{\text {flow }}$ and $R_{\text {iso }}$, given their strong linear correlation (0.966), show almost identical spatial patterns (accordingly, 
Table 1. Quantiles of residual DTM.

\begin{tabular}{rrrrrrrrrrrr}
\hline & $0 \%$ & $10 \%$ & $20 \%$ & $30 \%$ & $40 \%$ & $50 \%$ & $60 \%$ & $70 \%$ & $80 \%$ & $90 \%$ & $100 \%$ \\
\hline Residual (m) & -182.2 & -0.423 & -0.213 & -0.115 & -0.051 & -0.004 & 0.041 & 0.107 & 0.21 & 0.431 & 190.8 \\
\hline
\end{tabular}

Table 2. Quantiles of $R_{\text {flow }}$ and $R_{\text {iso }}$.

\begin{tabular}{lrrrrrrrrrrr}
\hline & $0 \%$ & $10 \%$ & $20 \%$ & $30 \%$ & $40 \%$ & $50 \%$ & $60 \%$ & $70 \%$ & $80 \%$ & $90 \%$ & $100 \%$ \\
\hline$R_{\text {flow }}(\mathrm{m})$ & 0.001 & 0.056 & 0.081 & 0.103 & 0.127 & 0.157 & 0.196 & 0.256 & 0.362 & 0.616 & 219.66 \\
$R_{\text {iso }}(\mathrm{m})$ & 0.001 & 0.062 & 0.088 & 0.11 & 0.133 & 0.162 & 0.201 & 0.258 & 0.355 & 0.587 & 98.04 \\
\hline
\end{tabular}
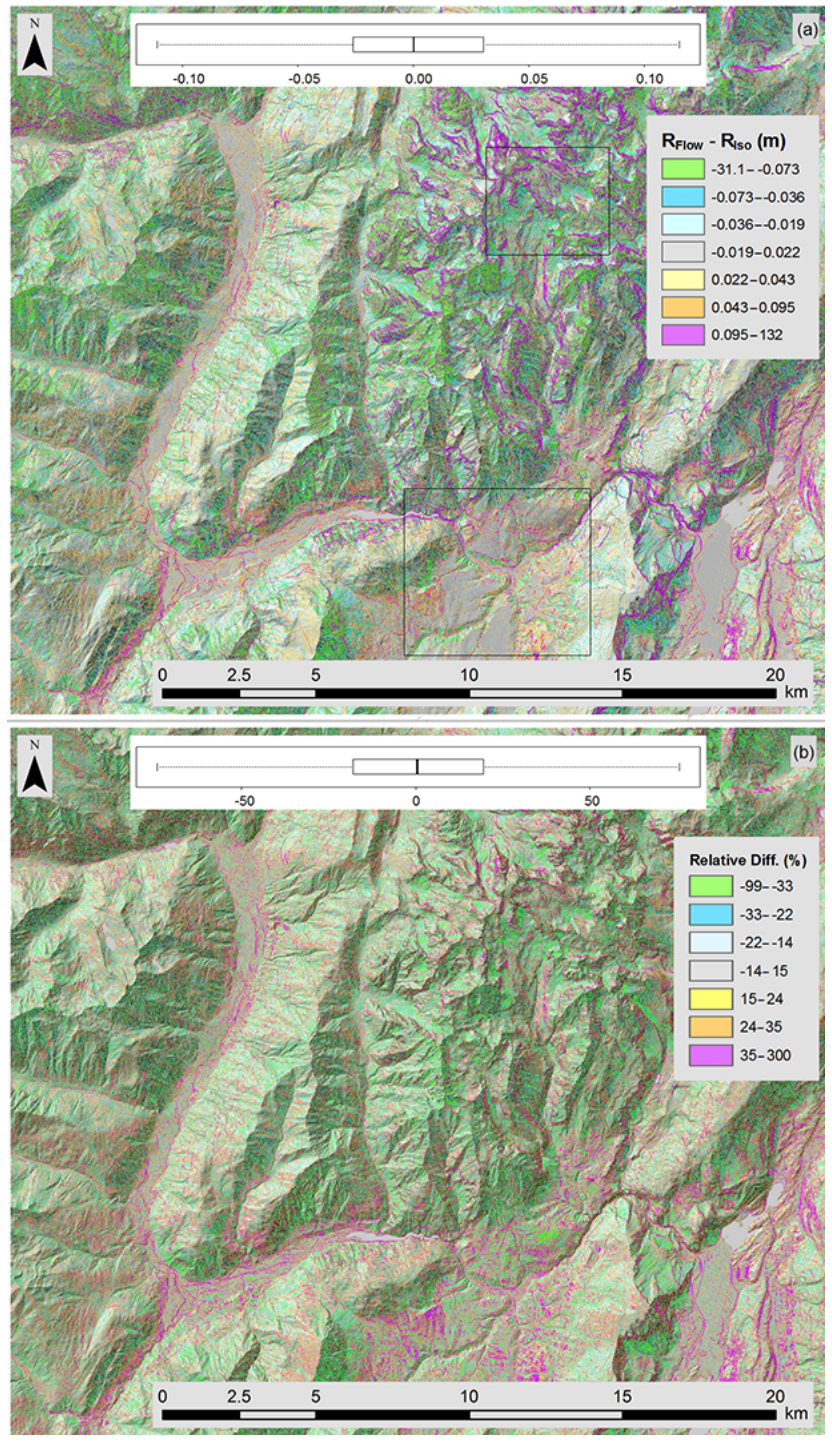

Figure 10. Differences and relative differences between $R_{\text {flow }}$ and $R_{\text {iso }}$ (color scales according to quantile classification). The areas represented in higher detail in the Figs. 11 and 12 have been highlighted. we show only one index: Fig. 9) and the statistical distributions of the values are also very similar (see Table 2). Similar to the residual elevations, most of the values of $R_{\text {flow }}$ and $R_{\text {iso }}$ are characterized by a limited range of variation, with a median value of approximately $0.15 \mathrm{~m}$; only $10 \%$ of the values show a short-range roughness (isotropic or flow-directional) of more than $0.6 \mathrm{~m}$.

To compare $R_{\text {flow }}$ and $R_{\text {iso }}$, we analyzed the differences and the relative differences between the two indices (Table 3). In terms of absolute values, the differences between the two indices are small, as expected given the values of the roughness indices (Table 2). Only $40 \%$ of the values have an absolute difference in roughness of more than $0.04 \mathrm{~m}$. Considering the variable accuracy of the DTM, with higher accuracy only in low-lying urbanized areas, the absolute differences on the order of $0.02 \mathrm{~m}$ or less have to be evaluated critically, even if these are associated with areas of low slope and with the highest accuracy. The relative differences effectively indicate that the two indices are quite different, with more than $40 \%$ of the values showing a relative absolute difference of more than $20 \%$. It is also interesting to note that, with the exception of the minimum and maximum values, the differences show a slightly positively distorted distribution.

With regard to the analysis of the spatial patterns (Fig. 10) of the differences and of the relative differences between the indices, it is interesting to analyze how these relate with morphological features. In areas of high altitude with no or limited anthropic influence (on morphology), the main differences between the two indices are clearly associated, as expected, with specific morphological features (Fig. 11). Zones with higher $R_{\text {flow }}$ than $R_{\text {iso }}$ are associated with fine-scale morphological features with an elongated shape almost orthogonal to the slope gradient, creating steps/scarps along the slope (Fig. 11). In the study area under analysis, the main morphologies exemplifying this behavior are (i) steps related to outcropping geological strata, (ii) fault and fracture lines at an angle with respect to the flow direction, (iii) landslides scarps, (iv) fluvial terrace scarps, and (v) glacial features (e.g., small frontal moraines). Zones in which $R_{\text {flow }}$ is less than $R_{\text {iso }}$ are associated with fine-scale morphological features with an elongated shape in the steepest descent direc- 
Table 3. Quantiles of the differences and the relative differences (Rel. diff. (\%)) between $R_{\text {flow }}$ and $R_{\text {iso }}$.

\begin{tabular}{lrrrrrrrrrrr}
\hline & $0 \%$ & $10 \%$ & $20 \%$ & $30 \%$ & $40 \%$ & $50 \%$ & $60 \%$ & $70 \%$ & $80 \%$ & $90 \%$ & $100 \%$ \\
\hline$R_{\text {flow }}-R_{\text {iso }}(\mathrm{m})$ & -31.064 & -0.073 & -0.036 & -0.019 & -0.008 & 0.001 & 0.009 & 0.022 & 0.043 & 0.095 & 131.8 \\
Rel. diff. (\%) & -99.225 & -33.632 & -22.353 & -13.9 & -6.494 & 0.535 & 7.685 & 15.306 & 24.064 & 35.519 & 300 \\
\hline
\end{tabular}

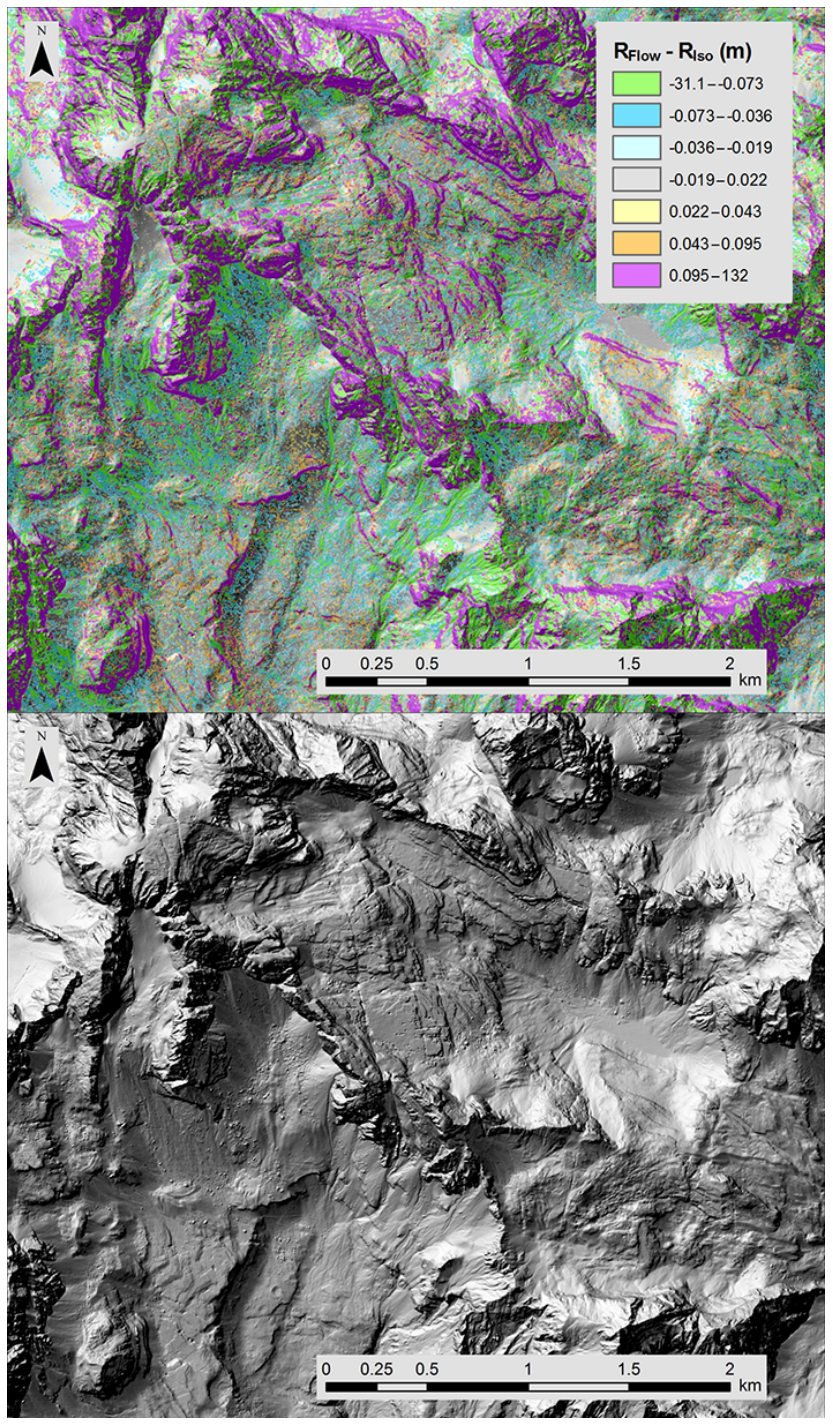

Figure 11. Differences between $R_{\text {flow }}$ and $R_{\text {iso }}$ in an area of high altitude with a limited anthropic influence. Purple features individuate elongated morphologies with the main axis oriented at right angle to slope (e.g., outcropping sub-horizontal geological strata). Light-green features individuate elongated morphologies with the main axis oriented along the slope (e.g., channels and other erosional features).

tion, e.g., channels in rocky outcrops and scree slopes; morphological features associated with erosional processes; debris/mud flow deposits; and structural lineaments elongated in the gradient direction.
The comparative analysis of the indices in areas with strong anthropic influence (Fig. 12) on the morphology highlights the impact of human activity on the landscape. In these areas, many anthropic morphological features show higher $R_{\text {flow }}$ than $R_{\text {iso }}$ : road and trail networks, terraces associated with agriculture or excavation activities, and urban areas. Anthropic morphological features leading to lower $R_{\text {flow }}$ than $R_{\text {iso }}$ are less common; channels directed along slope gradients and ski slopes are examples of this type of behavior.

Peculiarity is encountered in areas associated with agriculture (Fig. 13); these areas are characterized as extended zones with lower $R_{\text {flow }}$ than $R_{\text {iso }}$, with very small absolute differences (less than $0.01 \mathrm{~m}$ ) and considerable relative differences (more than $30 \%$ ). Considering the accuracy of the DTM, these small differences could be considered non-significant; however, comparing the shaded relief and the residual DTM with the orthophotos, it is evident that these areas display interesting morphological features related to the orientation of rows of orchards, e.g., for grapes or other agricultural crops. Consequently, from the side of bare-earth morphological analysis, these areas can be considered as artifacts of the HRDTM related to anthropic features and, in some circumstances, to sub-optimal filtering of the lidar points. However, from the perspective of soil science and the study of surface flow processes, this information could be valuable and provide a more correct evaluation of roughness to be used as an impedance factor.

These results are encouraging, suggesting that the use of $R_{\text {flow }}$ permits the extraction of useful information from HRDTMs. For example, in the context of geomorphologic interpretation, the maps of differences and relative differences between $R_{\text {flow }}$ and $R_{\text {iso }}$ represent useful geomorphometric indicators. In particular, these indicators are capable of discriminating between anisotropic surface textures elongated and orthogonal to the direction of the slope gradient; moreover, the spatial patterns of areas of positive and negative differences furnish interesting information on the spatial organization of the morphology, useful from the interpretative perspective as well as in the context of geodiversity considerations (Benito-Calvo et al., 2009; McGarigal et al., 2009; Melelli, 2014). Moreover, the areas with lower $R_{\text {flow }}$ than $R_{\text {iso }}$ often include areas of preferential flow; alternatively, areas with higher $R_{\text {flow }}$ than $R_{\text {iso }}$ exhibit features that act as an obstacle to flow. This type of segmentation of the morphological landscape can be quite useful from the perspective of water and/or sediment dynamics. Consequently, the differences between the two roughness indices becomes 


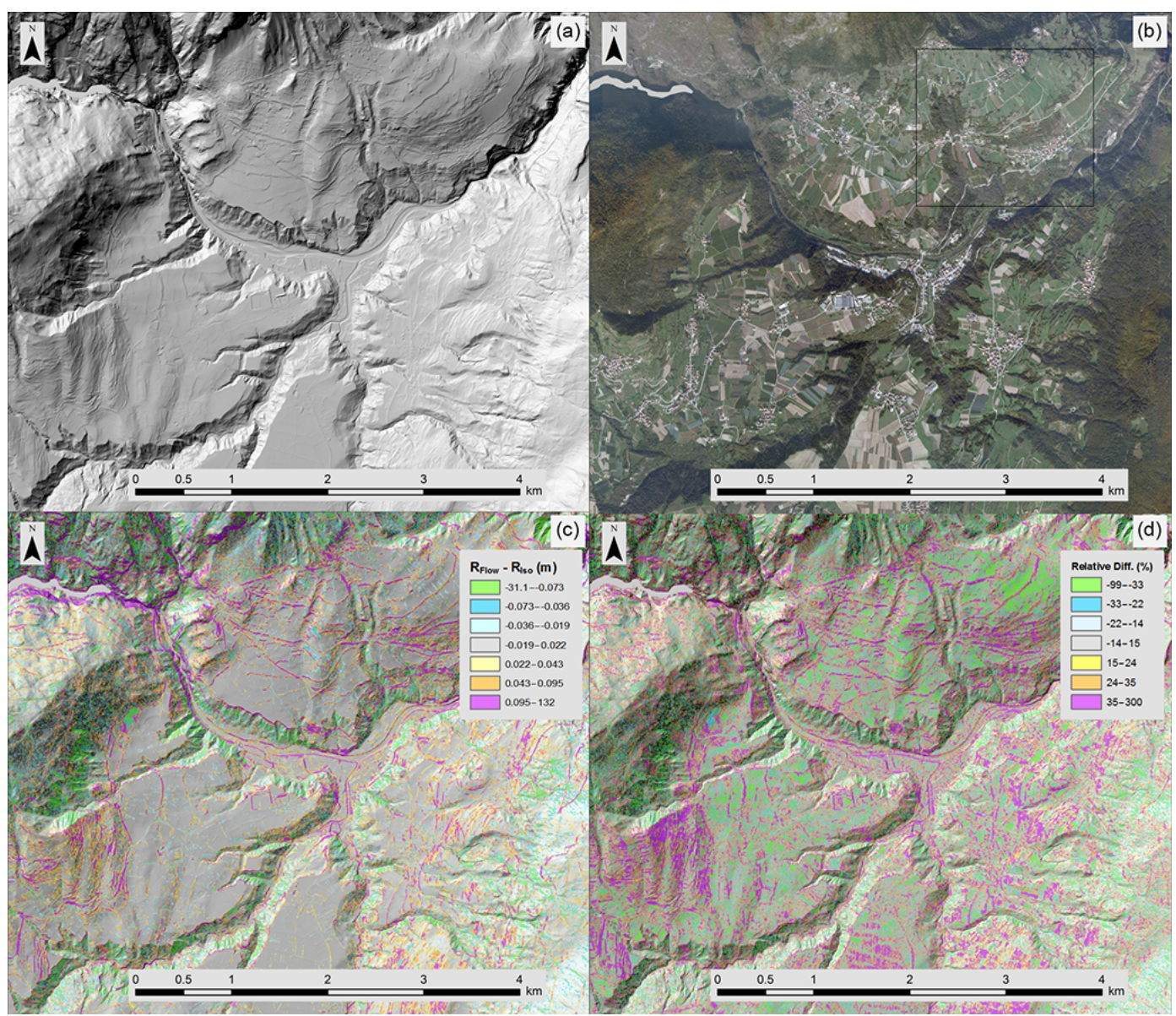

Figure 12. Differences and relative differences between $R_{\text {flow }}$ and $R_{\text {iso }}$ in highly anthropized environment. (a) Residual DTM, (b) orthophotos, (c) differences between $R_{\text {flow }}$ and $R_{\text {iso }}$, and (d) relative differences between $R_{\text {flow }}$ and $R_{\text {iso }}$. Terraces scarps and the road network are the main contributor of features (purple) with a higher $R_{\text {flow }}$ than $R_{\text {iso }}$. Areas with erosional processes located along the flanks of the main valleys are particularly highlighted by features (light green) with lower $R_{\text {flow }}$ than $R_{\text {iso }}$. For the highlighted area in (b) see Fig. 13 .

an index itself that can act as a new feature to be used in machine-learning approaches for automatic mapping (Bue and Stepinski, 2006; Cracknell and Reading, 2014; Macmillan et al., 2003) or for other predictive models, such as landslide susceptibility models (Booth et al., 2009; Jaboyedoff et al., 2010).

From the perspective of gravity-driven surface flow processes, the differences between $R_{\text {flow }}$ and $R_{\text {iso }}$, with the extensive presence of areas with lower $R_{\text {flow }}$ than $R_{\text {iso }}$, corroborate the hypothesis that this type of index can be a good candidate as an impedance factor in models and indices related to surface flow processes. The results of the proposed algorithm are reasonable and in accordance with the represented morphology. However, the small values characterizing the indices of roughness coupled with the difficult accuracy assessment that frequently characterize ALS HRDTMs suggest a careful analysis of the results. Moreover, the derivation of the residual DTM is crucial because it influences the subsequent steps of the roughness calculation. In fact, the small roughness values are partially related to the small absolute values of the residual DTM and consequently also partially to the procedure of residual DTM derivation.

\subsection{Applications to the sediment connectivity index}

In the next step of the analysis, we tested the impact of using $R_{\text {flow }}$ as an impedance factor in the topographical-based sediment connectivity index proposed by Cavalli et al. (2013a). In fact, one of the aims of the proposed index is to furnish an improved index of DTM-based roughness useful in the context of surface flow processes. To evaluate the impact of $R_{\text {flow }}$ on the connectivity index, we performed two runs of SedInConnect (Crema et al., 2015), a stand-alone tool developed to calculate the sediment connectivity index, using two different weighting factors ( $W_{\text {flow }}$ and $W_{\text {iso }}$ ), one derived from $R_{\text {flow }}$ and one from $R_{\text {iso }}$ according to Eq. (5). Subsequently, we derived two measures of the DC that we respectively name $\mathrm{DC}_{\text {flow }}$, the degree of connectivity derived using the weighting from $R_{\text {flow }}$, and $\mathrm{DC}_{\text {iso }}$, the degree of connectiv- 


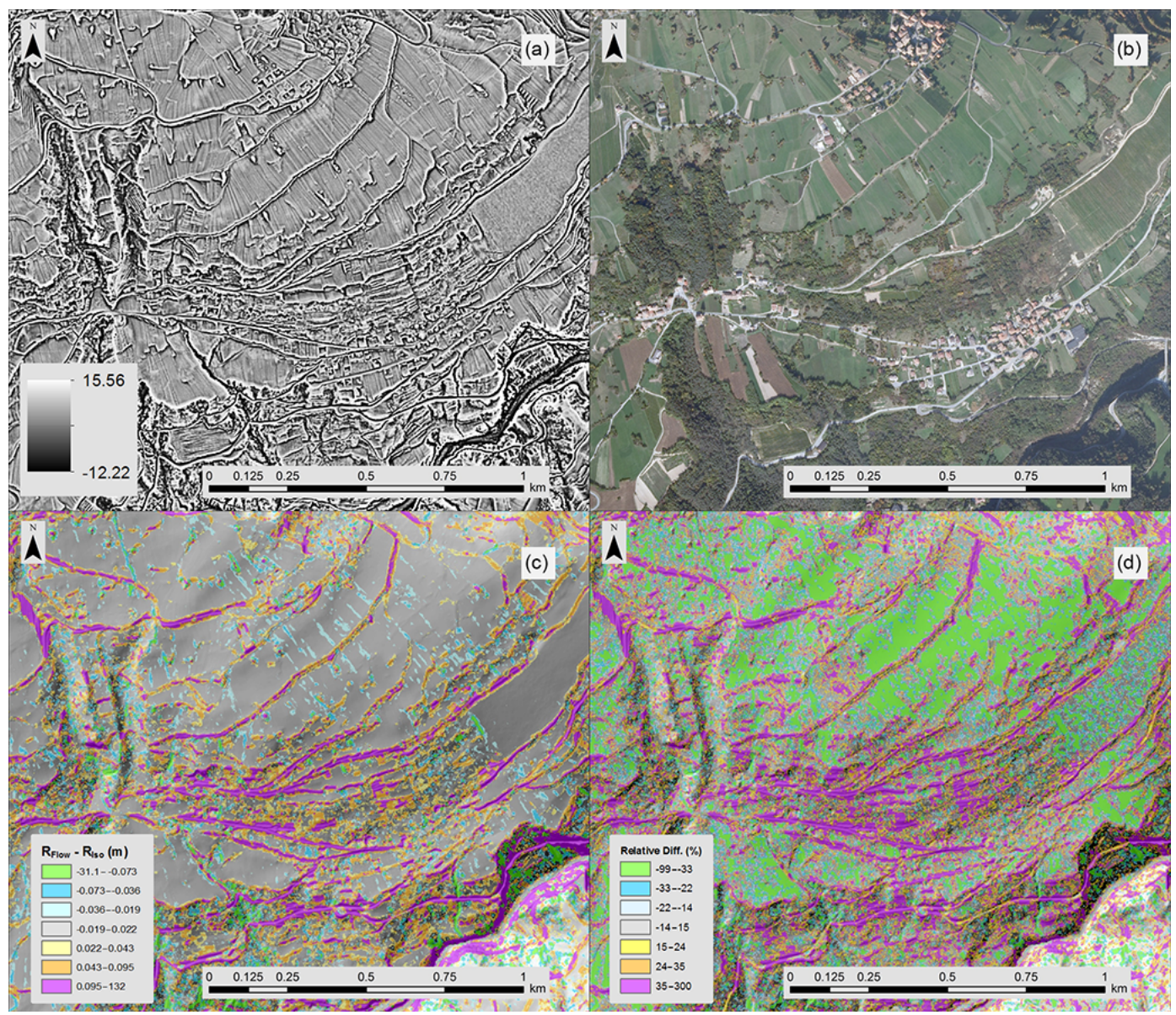

Figure 13. Detailed view of differences and relative differences between $R_{\text {flow }}$ and $R_{\text {iso }}$ in a highly anthropized environment. (a) Residual DTM, (b) orthophotos, (c) differences between $R_{\text {flow }}$ and $R_{\text {iso }}$, and (d) relative differences between $R_{\text {flow }}$ and $R_{\text {iso }}$. The areas with rows related to various agriculture crops are often characterized by striping artifacts in the DTM (see $\mathbf{a}$ and $\mathbf{b}$ ). In term of differences, these areas are slightly appreciable, having absolute values less than $0.02 \mathrm{~m}$; however, the impact on relative differences is significant, with areas (light-green features) with $R_{\text {flow }}$ lower than $30 \%$ of $R_{\text {iso }}$ in agreement with fields with rows aligned to flow direction.

Table 4. Roughness indices and impact on the weighting factor. The first two rows represent the quantiles of $R_{\text {flow }}$ and $R_{\text {iso }}$. The last two rows represent the quantiles of the relative differences between the roughness indexes $(R$ rel. diff. (\%)) and quantiles of the relative differences between weighting factors ( $W$ rel. diff. $(\%)$ ).

\begin{tabular}{lrrrrrrrrrrr}
\hline & $0 \%$ & $10 \%$ & $20 \%$ & $30 \%$ & $40 \%$ & $50 \%$ & $60 \%$ & $70 \%$ & $80 \%$ & $90 \%$ & $100 \%$ \\
\hline$R_{\text {flow }}(\mathrm{m})$ & 0 & 0.035 & 0.047 & 0.058 & 0.07 & 0.083 & 0.099 & 0.12 & 0.155 & 0.232 & 7.46 \\
$R_{\text {iso }}(\mathrm{m})$ & 0 & 0.0397 & 0.0522 & 0.0635 & 0.075 & 0.0872 & 0.1025 & 0.1232 & 0.1572 & 0.229 & 5.304 \\
$R$ rel. diff. (\%) & -93.186 & -32.961 & -22.785 & -15.242 & -8.647 & -2.347 & 4.054 & 11.017 & 19.184 & 30.091 & 233.33 \\
$W$ rel. diff. (\%) & -97.386 & -6.176 & -4.035 & -2.382 & -0.899 & 0.537 & 2.039 & 3.733 & 5.866 & 9.184 & 79.202 \\
\hline
\end{tabular}

ity derived using $R_{\text {iso }}$. The DC indices (Fig. 14) were derived considering the main channels of the Gadria and Strimm as targets, in accordance with the work by Cavalli et al. (2013a).

The residual DTM for roughness calculations has been derived with a single-pass moving average, using a $5 \times 5$ pixel window. The values of $R_{\text {flow }}$ and $R_{\text {iso }}$ show a similar statistical structure (Table 4) and spatial patterns. As at the previous study site, the areas in which $R_{\text {flow }}$ is lower than $R_{\text {iso }}$ are as- sociated with channels, erosional processes and debris-flow deposits; the areas in which $R_{\text {flow }}$ is greater than $R_{\text {iso }}$ correspond to rocky outcrops with steps/scarps related to structural lineaments and foliation of metamorphic rocks as well as road and trail networks (Fig. 14). It is important to note that the mapping from roughness values to the weighting factors reduces the impact of the relative differences between the two indices of roughness (Table 4). For example, by us- 

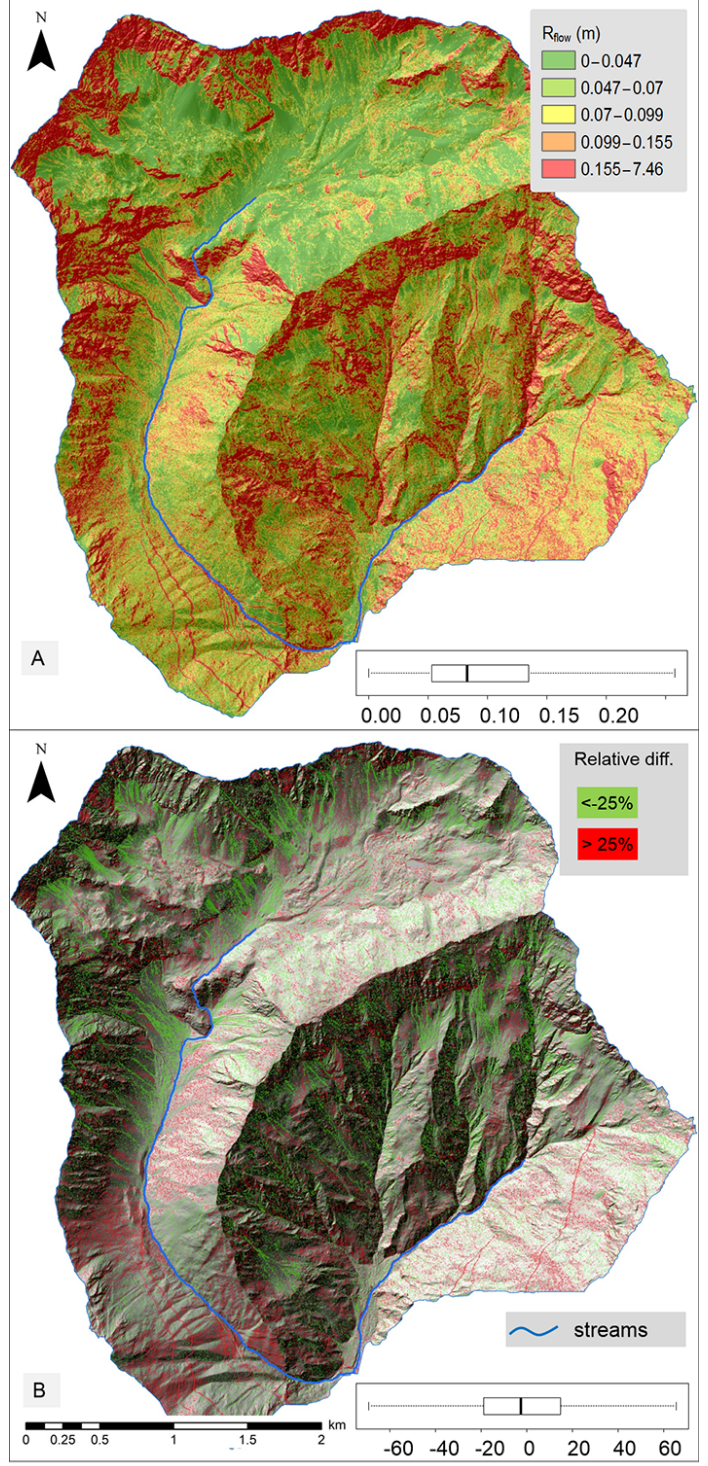

Figure 14. $R_{\text {flow }}$ (a) and relative differences between $R_{\text {flow }}$ and $R_{\text {iso }}$ (b). Areas with active sediment dynamics related to flow processes (erosion, transport and deposition) are highlighted by lower $R_{\text {flow }}$ values than $R_{\text {iso }}$ (green features).

ing the roughness indices, $10 \%$ of the area shows $R_{\text {flow }}$ values $32 \%$ lower than those of $R_{\text {iso }}$; alternatively, by using the weighting factors, $10 \%$ of the area shows $W_{\text {flow }}$ values $9.8 \%$ higher than those of $W_{\text {iso }}$ (the weighting factor is inversely proportional to roughness). This aspect, which is related to the fact that high relative differences between $R_{\text {flow }}$ with respect to $R_{\text {iso }}$ are associated with very small roughness values, clearly reduces the impact of differences in the roughness indices on the computation of DC.

The spatial patterns of the maps of DC computed with the two different weighting factors are apparently identical; the spatial comparison of the two indices was performed in terms
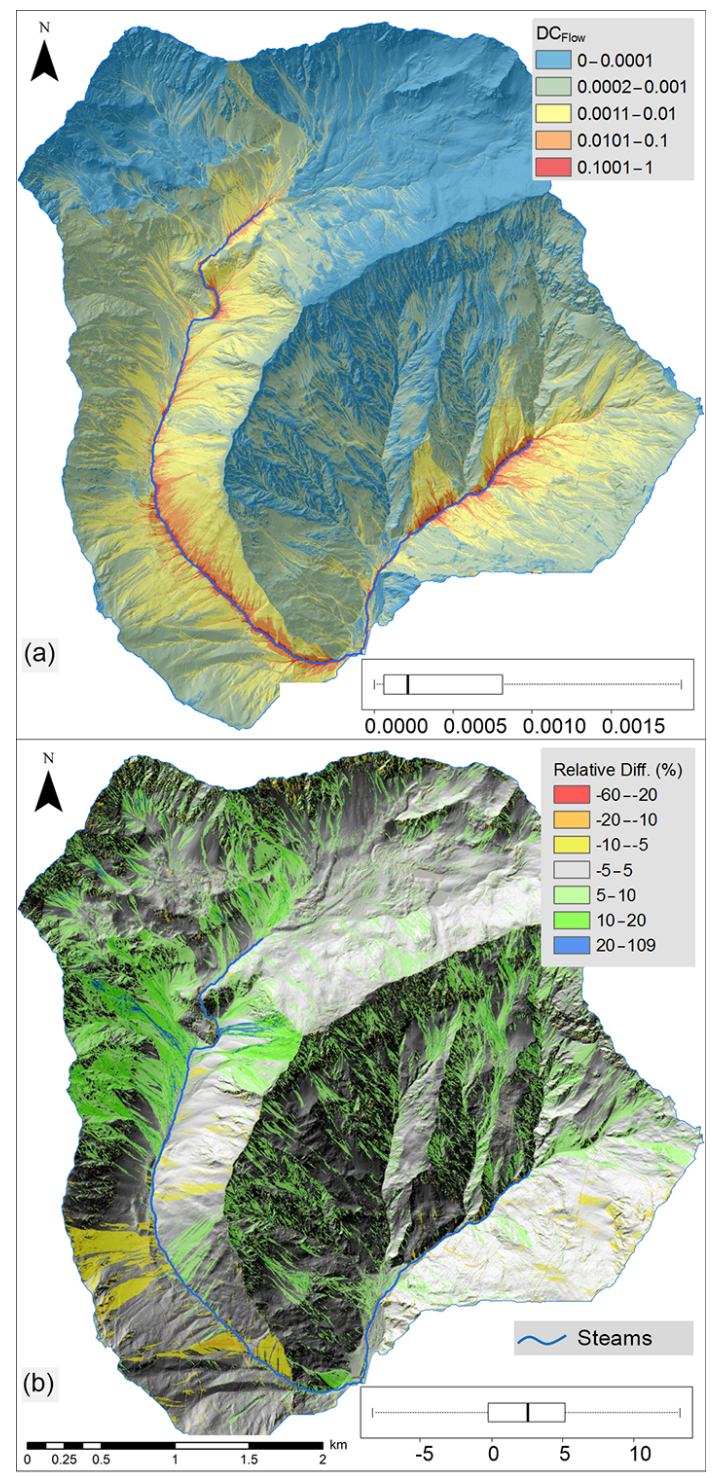

Figure 15. $\mathrm{DC}_{\text {flow }}$ distribution (a) and relative differences between $\mathrm{DC}_{\text {flow }}$ and $\mathrm{DC}_{\text {iso }}(\mathbf{b})$. The prevalence of areas with higher $\mathrm{DC}_{\text {flow }}$ than $\mathrm{DC}_{\text {iso }}$ is in accordance with the high activity of sediment dynamics in the studied basin.

of differences and relative differences. Given the low values of the DC, it is not surprising that small difference values were derived; a clearer picture can be obtained using relative differences (Fig. 15), from both a spatial and a statistical viewpoint. The analysis of Table 5 reveals that the differences and relative differences between $\mathrm{DC}_{\text {flow }}$ and $\mathrm{DC}_{\text {iso }}$ are relatively small.

The statistical distribution of DC relative differences is not symmetrical with the prevalence of areas with higher $\mathrm{DC}_{\text {flow }}$ than $\mathrm{DC}_{\mathrm{iso}}$, with $10 \%$ of the area showing $\mathrm{DC}_{\text {flow }}$ values that are $8.5 \%$ greater than those of $\mathrm{DC}_{\mathrm{iso}}$. Moreover, the analysis of relative differences versus $\mathrm{DC}_{\text {iso }}$ indicates that there is a prevalence of positive differences in areas of lower con- 
Table 5. Quantiles of $\mathrm{DC}_{\text {flow }}$ and comparison with $\mathrm{DC}_{\text {iso }}$.

\begin{tabular}{|c|c|c|c|c|c|c|c|c|c|c|c|}
\hline & $0 \%$ & $10 \%$ & $20 \%$ & $30 \%$ & $40 \%$ & $50 \%$ & $60 \%$ & $70 \%$ & $80 \%$ & $90 \%$ & $100 \%$ \\
\hline $\mathrm{DC}_{\text {flow }}$ & 0 & 0.00002 & 0.00004 & 0.00008 & 0.00013 & 0.00021 & 0.00036 & 0.0006 & 0.00115 & 0.00307 & 1 \\
\hline DC rel. diff. (\%) & -60.4 & -3 & -1 & 0.4 & 1.6 & 2.6 & 3.5 & 4.5 & 5.9 & 8.5 & 109.3 \\
\hline
\end{tabular}

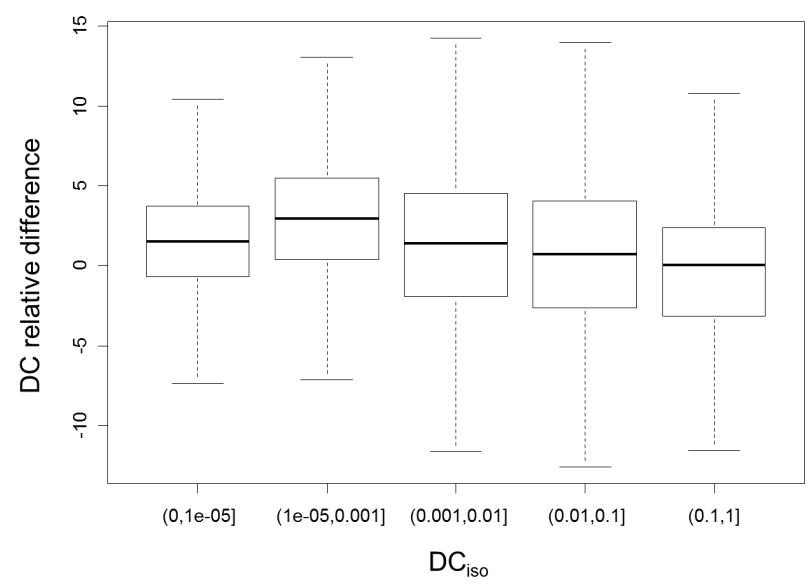

Figure 16. Box plot of relative differences (\%) between $\mathrm{DC}_{\text {flow }}$ versus $\mathrm{DC}_{\mathrm{iso}}$ grouped in classes of increasing $\mathrm{DC}_{\mathrm{iso}}$.

nectivity (Fig. 16); these areas are located far from the main stream network toward the headwaters; the shift in the statistical structure of differences is quite evident when the $\mathrm{DC}_{\text {iso }}$ is lower than 0.001. Even if the relative differences between the two indexes are small, their spatial pattern is quite meaningful (Fig. 17). As expected, the areas in which $\mathrm{DC}_{\text {flow }}$ is higher than $\mathrm{DC}_{\text {iso }}$ are located in areas of active sediment dynamics, where erosional and transport processes prevail. It is quite evident, for example (Fig. 17), that areas of higher connectivity with $\mathrm{DC}_{\text {flow }}$ are located in areas with prevalent erosional processes and evident sources of sediment.

The reliable spatial patterns of relative differences suggest that flow-directional roughness can be effective in the context of the sediment connectivity index. The use of flowdirectional roughness permits better description of the connectivity in areas with a prevalence of erosional processes. In fact, in agreement with gullies, $R_{\text {flow }}$ is lower than $R_{\text {iso }}$, because of it is not affected by the high variability in the slopes and channel banks. However, the small differences in DCs indicate the limited impact of flow-directional shortrange roughness with respect to isotropic roughness in this case study.

\section{Conclusions and further research}

The possibility of calculating directional roughness indices, such as short-range flow-directional roughness, has interesting potential. The morphological information extracted by the flow-directional roughness, also with its compari- son to isotropic roughness, can provide meaningful information from geomorphologic and geo-structural perspectives and for further quantitative usage. Flow-directionalbased indices could be quantitatively exploited in many geomodeling and geo-engineering contexts, such as geomorphological and lithological automatic mapping (e.g., Cracknell and Reading, 2014), landslide susceptibility models and geodiversity evaluations (Benito-Calvo et al., 2009; Booth et al., 2009). Flow-directional roughness is a better candidate than isotropic roughness to be used as a proxy of impedance to flow; this is particularly true in areas characterized by strong anisotropy in surface morphology (Trevisani and Rocca, 2015), with elongated morphological features aligned or orthogonal to the direction of flow. This is evident in areas of channelized erosion, where flow-directional roughness is significantly lower than isotropic roughness. Moreover, the ratio between flow-directional roughness and isotropic roughness can find application in multi-temporal studies focusing on morphology evolution (Darboux, et al., 2002).

In the context of the sediment connectivity index (Cavalli et al., 2013a), flow-directional roughness is a good index to be used as a weighting factor in the upslope and downslope components. In the case study analyzed, the differences between the degree of connectivity calculated using $R_{\text {flow }}$ and that calculated using $R_{\text {iso }}$ are more significant in terms of their spatial patterns than their values. The small differences between the two connectivity indices are partially related to the mapping from roughness values to the weighting factor that tends to decrease the impact of the roughness indices. Consequently, the derivation of the weighting factor from roughness values is a very delicate procedure that should be analyzed carefully, possibly taking into consideration the processes being modeled.

This study on the use of flow-directional roughness, together with positive and ready to use results, highlights some issues that require further investigation. To fully exploit the potential of flow-directional roughness as a physically based proxy of flow impedance, there are specific issues to be explored. The first topic is related to the derivation of the residual DTM at the base of the roughness calculation, as it influences all the subsequent steps of the analysis. There is the need to define a standardized procedure, e.g., a methodology and degree of smoothing, capable of specifically highlighting the residual topography with the proper wavelengths that is more significant in the context of flow dynamics. Moreover, as a second topic, this operation should be performed taking into consideration the available resolution of the DTM and 


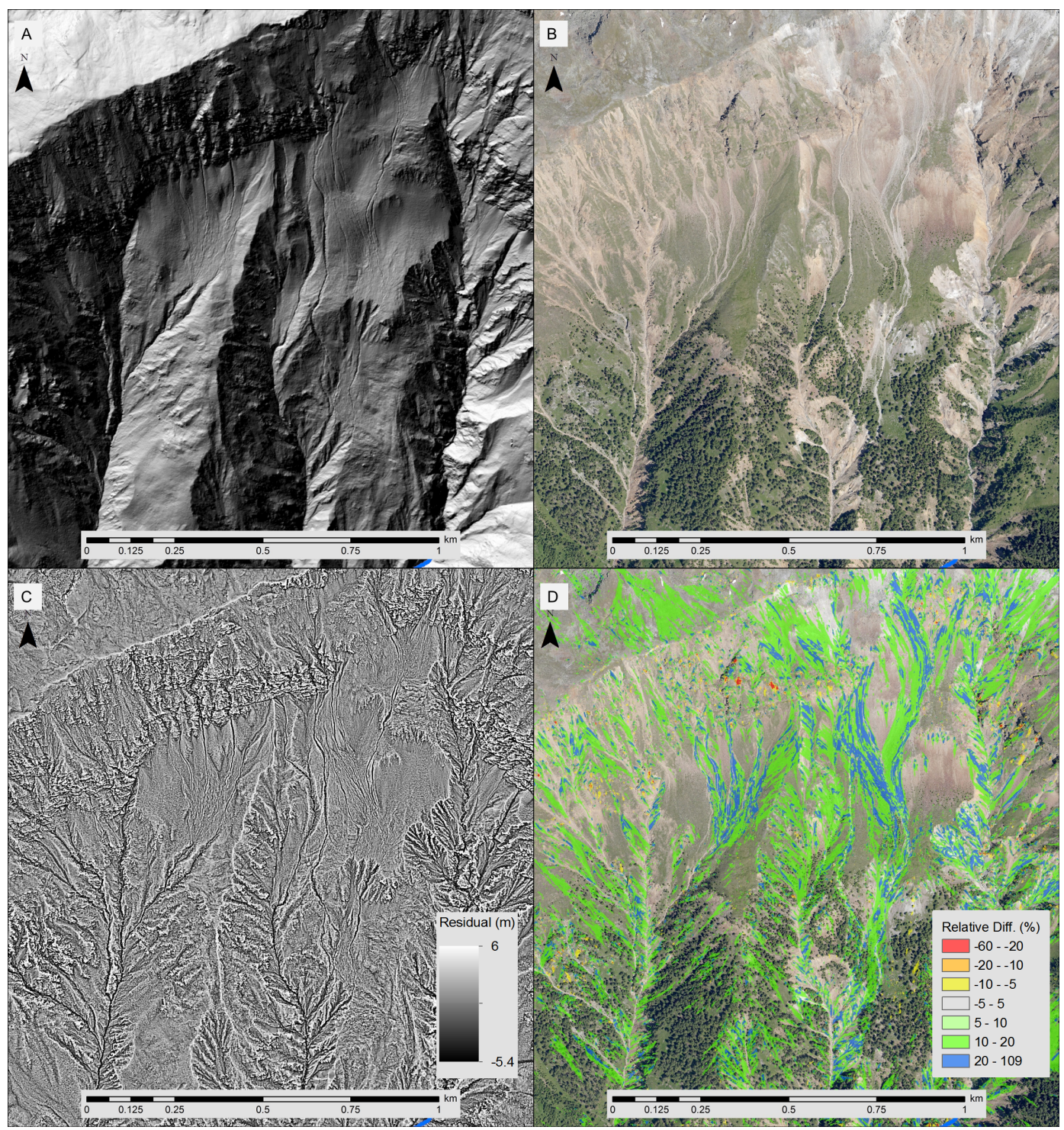

Figure 17. Detailed view of an area with active erosional processes; the good match between zones with higher $\mathrm{DC}_{\text {flow }}$ than $\mathrm{DC}_{\mathrm{iso}}$ and zones of active erosion, highlighted by the lack of vegetation, is evident.

also the fact that, given the typology of DTMs considered in this work, it is a 2.5-D representation of surface topography (Pollyea and Fairley, 2011).

A final topic worth exploring is related to the use of multiscale measures of directional roughness given that surface flow processes are influenced by roughness at a variety of scales. The multiscale evaluation of directional roughness in the context of flow-processes includes various open questions; among these, the choice of the maximum lag-distance to consider in the roughness calculation is the first critical point to be addressed. Another central point is related to how to synthesize, in a flow-dynamics-oriented perspective, the multiscale (i.e., at multiple lags) roughness indices (Balaguer et al., 2010; Smith, 2014).
Author contributions. S. Trevisani: study conception and design, analysis and interpretation of data, drafting of manuscript and image editing, and critical revision

M. Cavalli: interpretation of data analysis, drafting of manuscript, and critical revision

Acknowledgements. This work was partially conducted within the framework of COST Action ES1306: Connecting European Connectivity Research. In the research we made use of the MAD software tool freely available at https://github.com/cageo/Trevisani-2015 (Trevisani and Rocca, 2015).

Edited by: G. Sofia 


\section{References}

Atkinson, P. M. and Lewis, P.: Geostatistical classification for remote sensing: an introduction, Comput. Geosci., 26, 361-371, 2000.

Balaguer, A., Ruiz, L. A., Hermosilla, T., and Recio, J. A.: Definition of a Comprehensive set of texture semivariogram features and their evaluation for object-oriented image classification, Comput. Geosci., 36, 231-240, 2010.

Benito-Calvo, A., Pérez-González, A., Magri, O., and Meza, P.: Assessing regional geodiversity: The Iberian Peninsula, Earth Surf. Proc. Land., 34, 1433-1445, 2009.

Berti, M., Corsini, A., and Daehne, A.: Comparative analysis of surface roughness algorithms for the identification of active landslides, Geomorphology, 182, 1-18, 2013.

Booth, A. M., Roering J. J., and Perron, J. T.: Automated landslide mapping using spectral analysis and high-resolution topographic data: Puget Sound lowlands, Washington, and Portland Hills, Oregon. Geomorphology, 109, 132-147, 2009.

Borselli, L., Cassi, P., and Torri, D.: Prolegomena to sediment and flow connectivity in the landscape: A GIS and field numerical assessment, Catena, 75, 268-277, 2008.

Bue, B. D. and Stepinski, T. F.: Automated classification of landforms on Mars, Comput. Geosci., 32, 604-614, 2006.

Castellarin, A., Dal Piaz, G. V., Picotti, V., Selli, L., Cantelli, L., Martin, S., Montresor, L., Rigatti, G., Prosser, G., Bollettinari, G., Pellegrini, G. B., Carton, A., and Nardin, M.: Note illustrative della carta geologica d'Italia alla scala 1:50000, foglio 059 Tione di Trento, in: APAT and Dipartimento Difesa del Suolo - Servizio Geologico d'Italia, edited by: Trento, S. G.-P. A. T., 159 pp., 2005.

Cavalli, M. and Marchi, L.: Characterisation of the surface morphology of an alpine alluvial fan using airborne LiDAR, Nat. Hazards Earth Syst. Sci., 8, 323-333, doi:10.5194/nhess-8-3232008, 2008.

Cavalli, M. and Tarolli, P.: Application of LiDAR Technology for Rivers Analysis, Ital. J. Eng. Geol. Environ, 33-44, doi:10.4408/IJEGE.2011-01.S-03, 2011.

Cavalli, M., Tarolli, P., Marchi, L., and Dalla Fontana, G.: The effectiveness of airborne LiDAR data in the recognition of channel-bed morphology, CATENA, 73, 249-260, doi:10.1016/j.catena.2007.11.001, 2008.

Cavalli, M., Trevisani, S., Comiti, F., and Marchi, L.: Geomorphometric assessment of spatial sediment connectivity in small Alpine catchments, Geomorphology, 188, 31-41, doi:10.1016/j.geomorph.2012.05.007, 2013a.

Cavalli, M., Trevisani, S., Goldin, B., Mion, E., Crema, S., and Valentinotti, R.: Semi-automatic derivation of channel network from a high-resolution DTM: The example of an italian alpine region, Eur. J. Remote Sens., 46, 152-174, doi:10.5721/EuJRS20134609, 2013b.

Chilès, J.-P. and Delfiner, P.: Geostatistics - Modeling Spatial Uncertainty, John Wiley \& Sons, Inc., New Jersey, 734 pp., ISBN13: 978-0470183151, 2012.

Comiti, F., Marchi, L., Macconi, P., Arattano, M., Bertoldi, G., Borga, M., Brardinoni, F., Cavalli, M., D’Agostino, V., Penna, D., and Theule, J.: A new monitoring station for debris flows in the European Alps: first observations in the Gadria basin, Nat. Hazards, 73, 1175-1198, doi:10.1007/s11069-014-1088-5, 2014.
Cracknell, M. J. and Reading, A. M.: Geological mapping using remote sensing data: A comparison of five machine learning algorithms, their response to variations in the spatial distribution of training data and the use of explicit spatial information, Comput. Geosci., 63, 22-33, 2014.

Crema, S., Schenato, L., Goldin, B., Marchi, L., and Cavalli, M.: Toward the development of a stand-alone application for the assessment of sediment connectivity, Rendiconti Online Società Geologica Italiana, 34, 58-61, 2015.

Cressie, N. E.: Statistic for Spatial Data, revised edition, John Wiley \& Sons Inc., New York, 900 pp., ISBN-13: 9780471002550 , 1993.

Darboux, F., Davy, P., Gascuel-Odoux, C., and Huang, C.: Evolution of soil surface roughness and flowpath connectivity in overland flow experiments, Catena, 46, 125-139, 2002.

Dell'Agnese, A., Brardinoni, F., Toro, M., Mao, L., Engel, M., and Comiti, F.: Bedload transport in a formerly glaciated mountain catchment constrained by particle tracking, Earth Surf. Dynam., 3, 527-542, doi:10.5194/esurf-3-527-2015, 2015.

Fetter C. W.: Applied hydrogeology, Prentice Hall, New Jersey, USA, 4 edition, 598 pp., 2000.

Frankel, K. L. and Dolan, J. F.: Characterizing arid region alluvial fan surface roughness with airborne laser swath mapping digital topographic data, J. Geophys. Res. Earth Surf., 112, F02025, doi:10.1029/2006JF000644, 2007.

Gadelmawla, E. S., Koura, M. M., Maksoud, T. M. A., Elewa, I. M., and Soliman, H. H.: Roughness parameters, J. Mater. Process. Tech., 123, 133-145, 2002.

Garrigues, S., Allard, D., Baret, F., and Weiss, M.: Quantifying spatial heterogeneity at the landscape scale using variogram models, Remote Sens. Environ., 103, 81-96, 2006.

Glenn, N. F., Streutker, D. R., Chadwick, D. J., Thackray, G. D., and Dorsch, S. J.: Analysis of LiDAR-derived topographic information for characterizing and differentiating landslide morphology and activity, Geomorphology, 73, 131-148, 2006.

Grohmann, C. H., Smith, M. J., and Riccomini, C.: Multiscale Analysis of Topographic Surface Roughness in the Midland Valley, Scotland, IEEE Geosci. Remote S., 49, 1200-1213, doi:10.1109/TGRS.2010.2053546, 2011.

Herzfeld, U. C.: Master of the Obscure - Automated Geostatistical Classification in Presence of Complex Geophysical Processes, Math. Geosci., 40, 587-618, 2008.

Herzfeld, U. C. and Higginson, C. A.: Automated geostatistical seafloor classification - Principles, parameters, feature vectors, and discrimination criteria, Comput. Geosci., 22, 35-52, 1996.

Hiller, J. K. and Smith, M.: Residual relief separation: Digital elevation model enhancement for geomorphological mapping, Earth Surf. Proc. Land., 33, 2266-2276, 2008.

Hofle, B. and Rutzinger, M.: Topographic airborne LiDAR in geomorphology: A technological perspective, Z. Geomorphol., 55, 1-29, 2011.

Jaboyedoff, M., Oppikofer, T., Abellan, A., Derron, M.-H., Loye, A., Metzger, R., and Pedrazzini, A.: Use of LIDAR in landslides investigations: a review, Nat. Hazards, 61, 5-28, doi:10.1007/s11069-010-9634-2, 2010.

Lashermes, B., Foufoula-Georgiou, E., and Dietrich, W. E.: Channel network extraction from high resolution topography using wavelets, Geophys. Res. Lett., 34, L23S04, doi:10.1029/2007GL031140, 2007. 
Lucieer, A. and Stein, A.: Texture-based landform segmentation of LiDAR imagery, Int. J. Appl. Earth Obs., 6, 261-270, 2005.

Macmillan, R. A., Martin, T. C., Earle, T. J., and Mcnabb, D. H.: Automated analysis and classification of landforms using highresolution Digital Elevation Data: applications and issues, Can. J. Remote Sens., 29, 592-606, 2003.

McGarigal, K., Tagil, S., and Cushman, S. A.: Surface metrics: An alternative to patch metrics for the quantification of landscape structure, Landscape Ecol., 24, 433-450, 2009.

McKean, J. and Roering, J.: Objective landslide detection and surface morphology mapping using high-resolution airborne laser altimetry, Geomorphology, 57, 331-351, 2004.

Melelli, L.: Geodiversity: A new quantitative index for natural protected areas enhancement, Geojournal of Tourism and Geosites, 13, 27-37, 2014.

Pike, R. J.: Geomorphometry -diversity in quantitative surface analysis, Prog. Phys. Geog., 24, 1-20, 2000.

Pollyea, R. M. and Fairley, J. P.: Estimating surface roughness of terrestrial laser scan data using orthogonal distance regression, Geology, 39, 623-626, 2011.

Roy, S. G., Koons, P. O., Osti, B., Upton, P., and Tucker, G. E.: Multi-scale characterization of topographic anisotropy, Comput. Geosci., 90, 102-116, doi:10.1016/j.cageo.2015.09.023, 2015.

Smith, M. W.: Roughness in the Earth Sciences, Earth-Sci. Rev., 136, 202-225, doi:10.1016/j.earscirev.2014.05.016, 2014.

Sofia, G., Pirotti, F., and Tarolli, P.: Variations in multiscale curvature distribution and signatures of LiDAR DTM errors, Earth Surf. Proc. Land., 38, 1116-1134, 2013.

Tarboton, D.: A new method for the determination of flow directions and upslope areas in grid digital elevation models, Water Resource Research, 33, 309-319, 1997.
Teza, G., Marcato, G., Pasuto, A., and Galgaro, A.: Integration of laser scanning and thermal imaging in monitoring optimization and assessment of rockfall hazard: a case history in the Carnic Alps (Northeastern Italy), Nat. Hazards, 76, 1535-1549, 2015.

Trento Province, LiDAR specifications: available at: http://www.territorio.provincia.tn.it/portal/server.pt/community/ lidar/847/lidar/23954, last access: 15 April 2016,

Trevisani, S. and Rocca, M.: MAD: robust image texture analysis for applications in high resolution geomorphometry, Comput. Geosci., 81, 78-92, doi:10.1016/j.cageo.2015.04.003, 2015.

Trevisani, S., Cavalli, M., and Marchi, L.: Variogram maps from LiDAR data as fingerprints of surface morphology on scree slopes, Nat. Hazards Earth Syst. Sci., 9, 129-133, doi:10.5194/nhess-9129-2009, 2009.

Trevisani, S., Cavalli, M., and Marchi, L.: Reading the bed morphology of a mountain stream: a geomorphometric study on highresolution topographic data, Hydrol. Earth Syst. Sci., 14, 393405, doi:10.5194/hess-14-393-2010, 2010.

Trevisani, S., Cavalli, M., and Marchi, L.: Surface texture analysis of a high-resolution DTM: Interpreting an alpine basin, Geomorphology, 161-162, 26-39, 2012.

Westoby, M. J., Brasington, J., Glasser, N. F., Hambrey, M. J., and Reynolds, J. M.: "Structure-from-Motion" photogrammetry: A low-cost, effective tool for geoscience applications, Geomorphology, 179, 300-314, doi:10.1016/j.geomorph.2012.08.021, 2012.

Woodcock, C. E., Strahler, A. H., and Jupp, D. L. B.: The use of variograms in remote sensing: II. Real digital images, Remote Sens. Environ., 25, 349-379, 1988. 